This is an electronic reprint of the original article. This reprint may differ from the original in pagination and typographic detail.

Author(s): Unhjem, Astrid; Eklund, Kenneth; Nergård-Nilssen, Trude

Title: $\quad$ Early markers of language delay in children with and without family risk for dyslexia

Year: $\quad 2015$

Version:

Please cite the original version:

Unhjem, A., Eklund, K., \& Nergård-Nilssen, T. (2015). Early markers of language delay in children with and without family risk for dyslexia. First language, 35(3), 254-271. https://doi.org/10.1177/0142723715596122

All material supplied via JYX is protected by copyright and other intellectual property rights, and duplication or sale of all or part of any of the repository collections is not permitted, except that material may be duplicated by you for your research use or educational purposes in electronic or print form. You must obtain permission for any other use. Electronic or print copies may not be offered, whether for sale or otherwise to anyone who is not an authorised user. 
Title:

Early markers of language delay in children with and without family risk for dyslexia

Authors:

Astrid Unhjem

Assistant Professor

Department of Education

UiT - The Arctic University of Norway

9037 TROMS $\varnothing$

Norway

Phone: +47 776461 82/48 037798

E-mail: astrid.unhjem@uit.no

Kenneth Eklund

University of Jyväskylä

Finland

Trude Nergård-Nilssen

UiT - The Arctic University of Norway

Norway 


\title{
Early markers of language delay in children with and without family risk for dyslexia
}

\begin{abstract}
This study examined the extent to which receptive and productive vocabulary between ages 12 and 18 months predicted language skills at age 24 months in children born with family risk for dyslexia (FR) and a control group born without that risk. The aim was to identify possible markers of early language delay. We monitored vocabulary growth in 32 FR children and 21 control children longitudinally by using the Norwegian adaption of the MacArthur-Bates Communicative Development Inventories (Kristoffersen \& Simonsen 2012). Our results show different patterns in the two groups: We found a stronger interdependence of early receptive and productive vocabulary and a stronger stability in vocabulary growth in the second year of life in FR children than in controls. The combination of poor receptive vocabulary at 12 months and poor productive vocabulary at 18 months appeared to be important markers of later language delay in the FR group.
\end{abstract}

\section{Keywords}

Dyslexia, early language development, prediction, language delay, MacArthurBates CDI 


\section{Introduction}

Longitudinal studies have shown that children born with family risk for dyslexia (FR) are at increased risk of language delay and impairments. The Jyväskylä Longitudinal study of Dyslexia (JLD) in Finland found that FR children had a higher risk of protracted delay in productive language than typical children (P. Lyytinen, Eklund, \& Lyytinen, 2005; P. Lyytinen, Poikkeus, Laakso, Eklund, \& Lyytinen, 2001). A recent study by Nash, Hulme, Gooch, and Snowling (2013) found that nearly one third of FR children could be classified with specific language impairment (SLI) at $4 \frac{112}{2}$ years of age and that there thus seems to be an overlap in the language profiles observed in FR children and those in children with SLI in the early years. In general, SLI affects approximately 3\%-10\% of children (Tomblin et al., 1997). Taken together, these results highlight the importance of closely monitoring early language development in FR children. The present study examines the continuity and predictive relations in the early vocabulary development of FR children during their second year of life. More knowledge on this issue is urgent to target intervention to children at increased risk of language deficiencies, which may in turn also lead to difficulties in learning to read.

Dyslexia is a heritable, language-based learning disability characterised by poor decoding and spelling (Hulme \& Snowling, 2009; Lyon, Shaywitz, \& Shaywitz, 2003; Scarborough, 1990). Longitudinal studies have found that language delays starting at 2 years of age enhance FR children's risk of later reading and writing problems. Scarborough (1990) found shorter sentence length at 2.5 years in children who later 
developed reading difficulties. Torppa, Lyytinen, Erskine, Eklund, and Lyytinen (2010) found that receptive and expressive language at ages 2 and 2.5 years was associated with a broad pattern of oral language delays at ages 3.5.to 5.5 years and with reading difficulties at school age. At ages 3 through 6 years, phonological awareness, letter knowledge, verbal memory and non-word repetition have also been found to be among the most salient predictors of reading difficulties (H. Lyytinen, Aro, et al., 2004; Snowling, Gallagher, \& Frith, 2003; van Alphen et al., 2004).

So far, only a few studies have addressed the markers of language delay before 2-3 years of age and their relations to later language and reading difficulties among FR children. The JLD study has, however, followed FR children's language development longitudinally from early infancy into school age. Richardson, Leppänen, Leiwo, and Lyytinen (2003) found that at 6 months of age, the FR group was deficient compared to controls in speech perception, measured by the ability to categorise speech sounds in relation to duration. The first language measure that significantly distinguished the two groups was maximum sentence length at 2 years of age; the mean number of morphemes was 4.90 in the FR group compared to 5.75 among controls (H. Lyytinen, Aro, et al., 2004). Furthermore, the two groups displayed different predictive patterns in vocabulary development. Vocabulary comprehension at 14 months was associated with expressive language at 24 months in the FR group but not in the control group. Moreover, there were stronger predictive relations between vocabulary production at 24 months and all measures of receptive and productive language at ages 30 and 42 months in the FR group (H. Lyytinen et al., 
2001; P. Lyytinen et al., 2001). In addition, FR toddlers with a productive language delay at ages 24 and 30 months, particularly those who also had a receptive language delay, displayed patterns of more persistent delays in receptive and expressive language at 3.5 years and 5.5 years of age. In comparison, most late talkers in the control group caught up with their peers by 3.5 years (P. Lyytinen et al., 2005). In general, predictive associations between early language measures and reading at school age appeared earlier and were stronger in the FR group (H. Lyytinen, Ahonen, et al., 2004).

The longitudinal Dutch Dyslexia Program (DDP) followed FR children from the age of 2 months (van der Leij et al., 2013). This study found that FR children had poorer word production than controls at age 17 months. The growth curve analyses of 17-month and 23-month measures showed that the differences between the FR group and controls increased significantly over time. Moreover, the control group outperformed the FR group on various linguistic measures from ages 18 to 60 months. Differences in early word production seemed to be forerunners to linguistic differences between the groups at later ages (Koster et al., 2005; van Alphen et al., 2004). The DDP study also demonstrated that differences in early speech processing within a group of 26 FR children participating in this part of the study predicted later reading outcomes: The group of 10 children who developed reading disorders had deficient speech processing at age 2 months compared to those who developed normal reading skills. Speech processing was investigated by recording the event-related potentials (ERPs) of the children as they were presented different speech sounds (van der Leij et al., 2013; van Zuijen, Plakas, Maassen, Maurits, \& Leij, 2013). 
In summary, longitudinal studies have found that phonological deficits and a broad range of early language delays are associated with later language and reading difficulties in FR children. In addition, early language delays seem to be more persistent in FR children than in controls. More knowledge about the continuity of vocabulary development in FR children's second year of life is, however, still needed to recognise the early markers of language delay.

The heritability of language delay has also been studied in larger twin and cohort studies. Bishop, Price, Dale, and Plomin (2003) found significant, but small, genetic effects on low vocabulary at 2 years of age in their large-scale twin study. However, the heritability was significantly higher in 2-year-old late talkers who displayed persisting difficulties at 3 or 4 years of age. More recently, the Norwegian Mother and Child Cohort Study $(\mathrm{MoBa})$ found that the risk of persistent language delay between 3 and 5 years of age was significantly higher for children who had poor early gestures and language comprehension at 18 months and who were born with a family risk for language delay or reading difficulties. The study further showed that these children in general were at increased risk of language delay (Zambrana, Pons, Eadie, \& Ystrom, 2013). These findings stress the importance of early intervention in this group of children and demonstrate the possibility of identifying FR children at increased risk of language delay even before 2 years of age.

Longitudinal studies of language development in "typical children" who are without family risk of language or reading-related delay but suffer from expressive language delay at 2-3 years of age show that these children 
are also at increased risk of language or reading-related difficulties as they grow older (Bishop et al., 2003; Rescorla, 2002, 2005, 2009; Rice, Taylor, $\&$ Zubrick, 2008). Children who display a profile of poor productive language but normal receptive and cognitive skills are often referred to as late talkers (Heilmann, Weismer, Evans, \& Hollar, 2005; Rescorla, 2009; Rescorla, Roberts, \& Dahlsgaard, 1997). Fernald and Marchman (2012) found that 18-month-old late talkers obtained significantly lower vocabulary scores than their typically developing peers at 30 months. Nonetheless, more than half of the late talkers were within the normal range by 30 months. Rice et al. (2008) also found that a large portion of late talkers caught up with their peers later on. Taken together, these results suggest that the continuity between early vocabulary and later language skills may be weaker in typical children than in FR children.

Among other measures predicting language development in typical children, early perception of speech sounds seems to play an important role. Tsao, Liu, and Kuhl (2004) found that speech perception at age 6 months correlated with language abilities at ages 13 to 24 months. Bernhardt, Kemp, and Werker (2007) revealed relations between children's performance on a Switch task of minimal word pairs at 17 to 20 months of age and later language skills, which suggested that the ability to detect and use phonological distinctions is an important factor in language learning. Fernald and Marchman (2012) demonstrated that late talkers who also had poor efficiency in spoken word recognition at 18 months were less likely to catch up with their peers later on. Deficiency in speech processing could thus increase the risk of language delay. 
The present study aimed to investigate predictive relations in early vocabulary development in FR children and controls using the recently adapted Norwegian version (Kristoffersen \& Simonsen, 2012) of the MacArthur-Bates Communicative Development Inventories (CDI) (Fenson, 2007). CDI is one of the most widely used parent-report tools in assessing children's early language development, adapted to a wide range of languages (Kristoffersen, Simonsen, Bleses, et al., 2012), and it has been suggested to be useful in identifying toddlers who are at risk of language delay (Heilmann et al., 2005). However, Feldman et al. (2000) found only modest correlations between the CDI Words and Gestures form (CDI W\&G) at age 10-13 months and the CDI Words and Sentences form (CDI W\&S) at ages 22-25 months. Accordingly, Westerlund, Berglund, and Eriksson (2006) found that language delay at ages 2 and 3 years could not be reliably predicted from CDI at age 18 months due to low sensitivity. In their review of published studies, Law and Roy (2008) concluded that even if CDI is an effective and valid source of information regarding early language development, one should be cautious in using this tool to predict language delay. Note, however, that these studies were conducted on typical children. Because FR toddlers apparently do not catch up with their peers to the same extent that late talkers without family risk do (P. Lyytinen et al., 2005; Zambrana et al., 2013), the predictive value of CDI should be examined for FR children specifically. The validity of CDI in identifying FR children with language delay during their second year of life is still not well known. 
In summary, longitudinal studies indicate that FR children, who are late talkers at age 2-3 years are at increased risk of protracted language delay and reading difficulties. However, other studies have shown that maternal responsiveness (Tamis LeMonda, Bornstein, \& Baumwell, 2001), a high amount of language spoken directly to infants (Weisleder \& Fernald, 2013), joint attention and shared book reading (Farrant \& Zubrick, 2012), and overhearing others' conversations (Gampe, Liebal, \& Tomasello, 2012) might enhance children's language growth during their second year of life. Thus, this period might be important for early language-stimulating interventions. However, more knowledge on the early markers of language delay in FR children is required to develop and target early intervention to those at increased risk of language delay.

The aims of the present study were threefold. First, we aimed to investigate the continuity of language skills within the second year of life in FR children and in a Control group. Second, we aimed to examine the predictive relations between receptive and productive vocabulary from 12 months and productive language skills at 24 months. Third, we aimed to investigate whether FR children were at increased risk of becoming late talkers at 24 months and whether knowing a child's family risk status would improve the prediction of productive language delay at 24 months.

We outlined three specific research questions: 1) Is there a difference in the continuity of receptive and productive language measures at ages 12 , 15, 18 and 24 months between FR children and typical children? We hypothesised that there would be more and stronger relations between the language measures in the FR group than in the control group. 2) Is there a 
difference in the predictive power of receptive and productive vocabulary at ages 12,15 and 18 months regarding productive language at 24 months between FR children and typical children? We assumed that early language measures would explain more of the variation in productive language skills at 24 months in the FR group than in the control group. 3) Does family history of dyslexia a) add risk for being a late talker at 24 months and b) help in identifying late talkers at 18 months? We assumed that there could be more late talkers in the FR group than in the control group. We also assumed that regardless of the possible differences in late talkers within each group, the probability of correctly identifying children with productive language delay at 24 months would be higher in the FR group.

\section{Methods}

\section{Participants}

The 53 children reported here were drawn from the prospective Troms $\varnothing$ Longitudinal Study of Dyslexia (TLD). Of the 53 participants, 32 children met the criteria for family risk and formed our "FR group", and the remaining 21 children formed the "Control group". All 53 children were monolingual Norwegian, had no known neurological conditions, and had scored above 85 on a cognitive scale at age 24 months (Bayley, 2006). All children were tested at ages $12,15,18$ and 24 months, \pm 3 weeks. Thus, participants were the same age at all assessment times.

Sampling procedure. The families were recruited from the Troms $\emptyset$ area in North Norway via advertisements in local newspapers and brochures at local child health clinics. The families were selected in a three-stage procedure. In stage 1, parents who volunteered to participate in the study 
completed a short questionnaire. The questionnaire asked whether the parent had ever experienced reading and spelling problems and whether some of the parent's relatives (i.e., their own parents and siblings) had experienced reading and spelling problems (on a yes/no scale). In stage 2, parents were invited to a semi-structured interview. A detailed questionnaire was mailed to the parents before the interview. Parents who reported current impairments and/or a history of reading and writing impairments were asked to give a more detailed description in the interview. In stage 3 , all parents were tested on a wide battery of literacy tests to validate their self-reported reading and spelling abilities. Parents were also tested on a wide battery of reading-related cognitive skills (see Nergård-Nilssen and Hulme (2014) for a more detailed description of the tests and procedures employed).

Family risk. Previous family studies have used either parental selfreports or standardised tests to determine risk status (Gooch, Hulme, Nash \& Snowling, 2014). In the present study, children were classified as being at family risk if (i) a parent performed below -1 standard deviation on a literacy composite of non-word reading, text reading fluency and spelling, (ii) a parent self-reported as dyslexic and/or (iii) a parent reported a family history of dyslexia (i.e., literacy disorders in parents and siblings). According to these criteria, 32 children were classified as being at family risk for dyslexia (that is, they had at least one parent who met two of the three criteria).

Control group. Children whose parents performed within normal range on standardised literacy tests and reported no (family) history of literacy impairments formed our control group. According to these criteria, 21 children were allocated to the control group. 
Parent characteristics. All parents were monolingual, native speakers of Norwegian. There was no age difference between the Dyslexic group (mean $=34.3, S D=5.42)$ and the Control group $($ mean $=34.0, S D=5.22), t(71)=$ $0.27, p=.787$. As expected, there were large group differences in the three literacy measures used for classification purposes. For example, on the spelling test (with a maximum score of 40), the Dyslexic group obtained a mean score of 28 correct spelled words $(S D=5.55)$, whereas the Control group obtained a mean score of $35.7(S D=3.06), t(71)=7.67, p<.001$, Cohen's $d=1.82$. The Wechsler Abbreviated Scale of Intelligence (WASI) was used to obtain an estimate of parents' general cognitive ability (Wechsler, 1999; Ørbeck \& Sundet, 2007). The WASI test showed no difference between the Dyslexic group $($ mean $=117.45, S D=9.51)$ and the Control group $($ mean $=118.89, S D$ $=11.60$ ) in general cognitive ability: $t(71)=0.49, p=.623$. In terms of SES, the number of years of education completed after compulsory school was significantly higher among the parents in the Control group (mean $=3.95, S D=$ 2.46) compared to the Dyslexia group ( mean $=2.27, S D=2.74), t(71)=2.68$, $\mathrm{p}=.009$. However, the educational level in both groups was generally high, and the difference in education did not reflect differences in the total household income between the two groups: $t(71)=0.43, p=.966$ (Nergård-Nilssen $\&$ Hulme, 2014).

\section{Research design}

The TLD project employs a repeated-measures design to monitor how the FR and control group change over the passage of time. That is, children in the two groups undergo the same tests and procedures over a number of occasions. For the present study, we report the measures that 
were carried out repeatedly when the participants were aged 12, 15, 18, and 24 months.

\section{Materials}

For the present study, measures were selected to investigate children's early language skills.

\section{MacArthur-Bates Communicative Development Inventories}

(CDI). The Norwegian adaption of the CDI was used to assess receptive and productive vocabulary at ages $12,15,18$ and 24 months. The tool consists of two inventories: (1) the "Words and Gestures form" (8 to 20 months) and (2) the "Words and Sentences form" (16 to 36 months) (Kristoffersen \& Simonsen, 2012).

CDI "Words and Gestures" (CDI W\&G) was used to assess productive and receptive vocabulary at 12,15 and 18 months. The form consists of two parts, Part I - Early words and Part II - Actions and Gestures, each with several subtests. Part I contains four subtests: (1) First Signs of Understanding (3 items), (2) Phrases (26 items), (3) Starting to Talk (2 items), and (4) Vocabulary Checklist (396 items divided into 20 semantic categories (Kristoffersen \& Simonsen, 2012). In the present study, only the results from the Vocabulary Checklist in Part I were used. In this checklist, items marked "understands and says" yielded the W\&G Productive vocabulary score. The sum of items marked "understands and says" and items marked "understands" yielded the W\&G Receptive vocabulary score.

CDI: "Words and Sentences" (CDI W\&S) was used to assess productive vocabulary at 18 and 24 months. Our main reason for using both 
the CDI forms at 18 months was that we wanted to assess the correlations between them in productive vocabulary. The CDI W\&S form consists of two parts. Part I: Words Children Use contains two subtests: (1) Vocabulary Checklist (731 items divided into 22 semantic categories) and (2) How Children Use Words (5 items) (Kristoffersen \& Simonsen, 2012). In the present study, only the results from subtest (1), Vocabulary checklist, were used. Items marked as "says" in each of the 19 semantic subcategories of the Vocabulary Checklist were summed to yield the W\&S Productive vocabulary score (maximum score of 731). The results from Part II Sentences and Grammar were not used in this part of the study.

The Cronbach's alpha coefficient for internal consistency reliability for scores from the CDI W\&G varies, according to the manual, between .9099. For CDI W\&S Vocabulary checklist, Cronbach's alpha coefficient is reported to be .99 (Kristoffersen, Simonsen, Eiesland, \& Henriksen, 2012).

The Bayley Scales of Infant Development, 3rd edition (BSID-III)

- Language Scale. This individually administered test covering ages 1-42 months was used to assess receptive and expressive communication at 24 months. However, only the latter is used here. The Bayley's Expressive Communication subtest assesses the child's ability to vocalise, name pictures and objects, and communicate with others. The subtest includes assessments of preverbal communications such as gesturing, joint referencing, turn taking, vocabulary development such as naming objects, pictures and actions, and morpho-syntactic development such as the use of two-word utterances and the use of plurals and verb tense. The average reliability for the language scale is $\alpha=.93$ (Bayley, 2006). 


\section{General procedure}

All children were tested individually. Assessments were administered in a laboratory at the university and were videotaped and audio-recorded for later analyses. Each session lasted 1-2 hours and was completed with both the examiner and one parent in the room. Parents received and completed a CDI form regarding their child's receptive and expressive vocabulary at home a day or two before the visit to the university laboratory. The CDI forms were inspected by the examiners at the clinic to identify possible errors.

\section{Results}

Distributions were normal or close to normal in all measures except in W\&G Receptive vocabulary (12 months) and W\&G Productive vocabulary (18 months) in the CDI W\&G, which were right-skewed. Logarithmic transformations were used for these two measures to attain normality. Four scores in four different measures were identified as outliers, exceeding \pm 3.3 in the $\mathrm{z}$-score. These scores were moved to the tail of the distributions, i.e., to one unit above the next most extreme value, as recommended by Tabachnick and Fidell (2013). The order of the participants was retained, and no participants were dropped from the sample.

The descriptive statistics and group comparisons in language measures are presented in Table 2. There were no significant differences between the FR and the Control group in any of the language measures, and the effect sizes were small, except in W\&G Receptive vocabulary at 15 and 18 months, in which the effect sizes were moderately in favour of the Control group. Furthermore, the variances were equal in the two groups, 
except in W\&G Productive vocabulary at 15 months, where the variance was larger in the FR group $(\mathrm{F}(2,51)=6.26, \mathrm{p}<.05)$.

Pearson correlations were used to study the first research question, that is, the strength of the relationship and continuity between language measures during the second year of life. The arithmetic mean of the standardised values of W\&G Productive vocabulary and W\&S Productive vocabulary was used as the measure of Composite Productive vocabulary at 18 months because high correlations were found between these measures in both the FR $\left(.89^{* * *}\right)$ and the Control group $\left(.96^{* * *}\right)$. Likewise, Composite Productive language at 24 months was computed from the arithmetic mean of the standardised values of W\&S Productive vocabulary and Bayley's Expressive communication because of high correlations between the measures $\left(.71^{* * * *}\right.$ and $.83^{* * *}$ for the FR and the Control group, respectively).

The correlations between the language measures at 12, 15, 18 and 24 months of age are presented separately in the FR and the Control group in Tables $3 a$ and $3 b$, respectively. In the FR group, all early receptive and productive vocabulary measures at 12,15 , and 18 months correlated significantly with each other and with Composite Productive language at 24 months of. In the Control group, significant correlations were found within each domain; all measures of Receptive vocabulary at ages 12, 15, and 18 months correlated significantly with each other, and within Productive vocabulary, measures from 12 and 15 months and from 15 and 18 months correlated significantly with each other. In addition, W\&G Productive vocabulary at 12 months and Composite Productive vocabulary at 18 months correlated significantly with Composite Productive language at 24 
months in this group. The only significant correlations between Receptive and Productive vocabulary were found at 12 months, and between W\&G Productive vocabulary at 12 months and W\&G Receptive vocabulary at 18 months. In addition, W\&G Receptive vocabulary at 12 months correlated significantly with Composite Productive language at 24 months.

Differences between the FR and the Control group in the correlation coefficients were tested using Fisher's Z-transformed correlation coefficient (McNemar, 1969). Four predictive correlations concerning the relations between receptive and productive language were stronger in the FR group: W\&G Receptive vocabulary at 12 months correlated more strongly with W\&G Productive vocabulary at 15 months (.69 vs. -.04) and with Composite Productive vocabulary at 18 months (.67 vs. .14). W\&G Receptive vocabulary at 15 months correlated more strongly with W\&G Productive vocabulary at 15 months (.81 vs. .04) and Composite Productive vocabulary at 18 months (.56 vs. -.06).

Our second research question addressed the predictive power of receptive and productive vocabulary at 12,15 and 18 months regarding productive language at 24 months and whether there was a difference in the predictive power observed in FR children and typical children. For these purposes, we performed hierarchical regression analyses separately for the FR group and the Control group. At each of the three steps, both predictors (receptive and productive vocabulary) from one age (12, 15, and 18 months) were added using a STEPWISE method to see which of the measures had significant predictive power in addition to measure(s) of the previous age(s). The results are presented in Table 4. In the FR group, W\&G Receptive 
vocabulary (12 and 18 months) along with Composite Productive vocabulary (18 months) explained $65.2 \%$ of the variance in Composite Productive language at 24 months $(F(3,27)=15.00, \mathrm{p}<.001)$. At the age of 12 months, W\&G Receptive vocabulary was the better predictor, explaining $27.5 \%$ of the variance in Composite Productive language. After including W\&G Receptive vocabulary at 12 months in the model, Composite Productive vocabulary at 18 months added an explanatory power of $29.5 \%$, and after putting the two measures in the model, W\&G Receptive vocabulary from the same age added an explanatory power of $8.2 \%$. In the Control group, W\&G Productive vocabulary at 12 months was the only significant predictor, explaining $34.1 \%$ of the variance in Composite Productive Language at 24 months $(F(1,19)=5.37, \mathrm{p}<.05)$. Because the inequality of the sample sizes in the two groups could have affected the probability of the predictors to be included in regression models above, we ran confirmatory regression analyses in both groups. Here, we entered the four predictors that were significant in either of the two groups in the model (i.e., W\&G Productive vocabulary and W\&G Receptive vocabulary at 1.0 and 1.6 years). The variances explained in Composite Productive language at 24 months were $65.2 \%(\mathrm{~F}(4,23)=10.79, \mathrm{p}<.001)$ and $49.5 \%(\mathrm{~F}(4,15)=$ 3.68, $\mathrm{p}<.05$ ) in the FR group and Control group, respectively.

To study the first part of the third research question, i.e., whether a family history of dyslexia added the risk of being a late talker at 24 months, we first classified children as being a late talker or not. In line with Fernald and Marchman (2012), late talkers were identified as children with scores below the $20^{\text {th }}$ percentile on CDI W\&S Productive Vocabulary. As 
recommended by Simonsen, Kristoffersen, Bleses, Wehberg, and Jørgensen (2014), we used the gender-specific norms of the Norwegian adaption of CDI. Using these criterion, 11 children in the FR group and 7 children in the Control group were identified as late talkers. The number of late talkers did not differ between the two groups according to the chi-square test $\left(\chi^{2}(1, N=\right.$ $53)=.006, \mathrm{p}=.94)$

We used logistic regression analyses separately for the two groups to study the second part of the third research question, i.e., whether the knowledge of a child's familial risk resulted in a better identification of children with language delay at the age of 24 months one half year before the classification. W\&G Receptive vocabulary and W\&G Productive vocabulary at 18 months were entered into the model using the Forward Wald procedure with a probability level .05 for a measure to be entered into the model and the most commonly used cut-off level (=.50). In the FR group, a model with W\&G Productive vocabulary at 18 months as a predictor turned out to be significant $\left(\chi^{2}=18.68, \mathrm{p}<.001\right.$ with $\mathrm{df}=1$; see Table 5). Nagelkerke's $\mathrm{R}^{2}$ of .61 indicated a strong relationship between prediction and grouping. The model correctly identified 9 out of 11 children as late talkers (sensitivity $=81.8 \%$ ). All children who were correctly identified had a score at or below the $15^{\text {th }}$ percentile (gender specific) at 18 months. Moreover, the model correctly identified that 18 of the 21 children were not late talkers (specificity $=85.7 \%$ ). In the Control group, neither receptive nor productive vocabulary at 18 months could reliably identify children with language delay; that is, both predictors were non-significant.

\section{Discussion}


Our first aim was to investigate continuity in receptive and productive language development within the second year of life in FR children and controls. In line with our expectations, we found more and stronger concurrent and predictive relations between language skills in the FR than in the Control group. All vocabulary measures from ages 12 to 18 months correlated with each other and with productive language at age 24 months in the FR group. Within the Control group, correlations were fewer and more domain specific (i.e., receptive and productive vocabulary). These results correspond well with the JLD study, where predictive relations between early and later language skills tended to be weaker and less consistent in the group of typical children (H. Lyytinen, Ahonen, et al., 2004; H. Lyytinen et al., 2001; P. Lyytinen et al., 2001). Notably, we found strong correlations between receptive vocabulary starting at age 12 months and productive language at age 24 months only in the FR group. These findings are in line with those of P. Lyytinen et al. (2005), who found that FR children with expressive and receptive language delay were those most at risk of protracted delays. Taken together, our results indicate that receptive and productive language are more tightly intertwined from 12 months of age in FR children than in typical children.

In both the FR group and the Control group, productive vocabulary at ages 12 and 18 months correlated significantly with productive language at 2 years of age. Feldman et al. (2000) found predictive correlations between productive vocabulary at 1 and 2 years of age in typical children. Similarly, Fernald and Marchman (2012) found predictive relations between productive vocabulary at age 18 months and expressive vocabulary at age 
30 months, and Westerlund et al. (2006) found that productive vocabulary was the best CDI variable at age 18 months in predicting language delays at 3 years of age. The results from our study correspond well with these studies and extend previous research by finding such predictive relations in the FR group as well as in typical children.

Our second research question aimed to investigate possible differences between FR children and controls regarding the predictive power of receptive and productive vocabulary at ages 12,15 and 18 months for productive language skills at 24 months. In the FR group, early language measures explained $65 \%$ of the variance in productive language at 24 months, with receptive vocabulary at 12 and 18 months being the strongest predictors. In the Control group, on the contrary, only one third of the outcome in productive language at 24 months was explained by productive vocabulary at 12 months. A limitation of our study, however, is that the smaller sample size in the Control group might have affected the results. Confirmatory analyses revealed a somewhat higher variance explained in this group. Nonetheless, in support of our results, they correspond well with the Finnish study (H. Lyytinen, Ahonen, et al., 2004; H. Lyytinen et al., 2001; P. Lyytinen et al., 2001), finding stronger continuity in the language development in FR children than in controls. Our results add to previous research by suggesting that receptive vocabulary as early as 12 months of age might be a strong predictor of productive language at 24 months of age but only in the FR group.

Our study indicates that the relative contribution of receptive and productive language is different between the FR and the Control group, with 
a stronger predictive relationship between early receptive vocabulary and later productive language among FR children. A possible explanation for this could be more variation in early speech processing within the FR group. Several studies have revealed strong links between speech processing before 12 months of age and later language outcomes (see Kuhl, Conboy, Padden, Nelson, and Pruitt (2005) for a review). Deficiencies in early speech processing among FR children have been found in the JLD study (Richardson et al., 2003) and in the DDP program (van der Leij et al., 2013; van Zuijen et al., 2013). However, of special interest to our study, van Zuijen et al. (2013) found retrospectively a difference within the FR group in speech processing at age 2 months. FR children who later developed reading difficulties were inferior in speech processing compared to FR children who became normal readers. We suggest that individual variations in early speech processing skills within the FR group may be reflected in variations in receptive vocabulary at 12 months and in stronger predictive relations between early receptive vocabulary and later language outcomes in this group compared to typical children.

Our third research question addressed the issue of whether a family history of dyslexia added to the risk of being a late talker at 24 months and whether knowledge about children's family risk status could facilitate the identification of late talkers as early as 18 months of age. Regarding the first part of the question, we found no group differences in the amount of late talkers or in productive language at 18 or 24 months. These findings are contradictory to those of the Dutch study (DDP), which found group differences in word production as early as 17 months, in favour of typical 
children (Koster et al., 2005), and more in line with the Finnish study (JLD), which found no differences between the two groups in vocabulary production at 24 months (P. Lyytinen et al., 2001). Our results indicate that early vocabulary in 24-month-old FR children is not different from early vocabulary levels in typical children and that belonging to the FR group alone does not increase the risk of being a late talker at this age.

Regarding the second part of the question, i.e., whether knowing the family risk status of a child could help in the early identification of late talkers, we found that productive vocabulary at 18 months was a significant predictor of language delay at 24 months in the FR group but not in the Control group. The findings in the Control group are in line with earlier studies of typical children, suggesting caution in predicting language delay at this early age (Law \& Roy, 2008; Westerlund et al., 2006). The results of the FR group, on the contrary, converge well with the JLD study by showing that the predictive relations between vocabulary production were stronger in the FR group compared to controls (H. Lyytinen et al., 2001; P. Lyytinen et al., 2001). Whereas the Finnish study found this difference in predictive relations from 24 months onwards, our study found the same pattern (i.e., differences in predictive relations) as early as 18 months of age. Moreover, we found high values of sensitivity and specificity when using Productive vocabulary on the CDI W\&G at 18 months in predicting language delay at 24 months in the FR group. All correctly classified late talkers in this group had a score below the $15^{\text {th }}$ percentile on $\mathrm{W} \& \mathrm{G}$ Productive vocabulary at 18 months. These results suggest that Productive vocabulary in the CDI W\&G could serve as a marker of language delay as 
early as 18 months of age among FR children. However, because the present study is, to our knowledge, one of the first to report longitudinal data based on the Norwegian adaption of the CDI, our findings need to be replicated in later studies.

Our study faces several limitations that must be taken into account. First, because of the rather small group size in our study, we need to be cautious in interpreting the results. Nonetheless, our results are strengthened by the fact that they are comparable and aligned with previous research. Another concern is that the FR and Control parents differed in terms of their years of education. Several previous studies have revealed relations between children's language development and parents' SES (see Tamis-LeMonda, Baumwell, and Cristofaro (2012) for a review). However, because there were no differences between the two groups in our study in household income and the education level in both groups was generally high, we believe the differences in education had minimal effect on our results.

A third limitation is that we followed children only up to 24 months. This is a rather early age at which to identify late talkers, even if several studies indicate productive language at this age is a salient early marker of language delay in FR children and children without risk (Bishop et al., 2003; P. Lyytinen et al., 2005; Rescorla, 2011). In a future study, we will examine whether poor productive vocabulary at 18 months and 24 months is a marker of persistent language delays in the FR group and address key findings in the study by Nash et al. (2013), which showed that almost one third of FR children could be classified as having SLI at $4 \frac{1}{2} 2$ years of age. 
In general, one should be cautious in interpreting language delay based on CDI vocabulary measures during a child's second year of life (Law \& Roy, 2008). Lexical development at this age in characterised by substantial individual variation, and the majority of children with language delay at this age catch up later on (Rice et al., 2008). In addition, because vocabulary development is highly influenced by other language-related domains, such as speech perception (i.e.Tsao et al. (2004)), and environmental factors, such as maternal responsiveness (Tamis LeMonda et al., 2001), exposure to spoken language (Gampe et al., 2012; Weisleder \& Fernald, 2013), and shared book reading (Farrant \& Zubrick, 2012), prediction based merely on vocabulary measures might be too narrow. Nonetheless, Rescorla (2011) suggests that delay in early productive vocabulary might be a symptom, often secondary to a broader language delay. Our study indicates a stronger intertwinement between early receptive and productive language skills in FR children than in typical children. Poor productive vocabulary at 18 and 24 months could thus be a salient marker of a broader delay in language-related domains in the FR group. Taking into account the increased risk of having a protracted language delay for late talkers in this group (P. Lyytinen et al., 2005), the question emerges regarding whether health care clinics should follow the language development of FR children more closely during their second year of life to target intervention to children considered being at increased risk for language delays.

\section{Acknowledgements}


The Troms $\varnothing$ Longitudinal study of Dyslexia is supported by a grant from the

Troms $\emptyset$ Research Foundation (Grant number A42966) to the third author of

the paper. We thank all families who took part in the study.

\section{References}

Bayley, N. (2006). Bayley Scales of Infant and Toddler Development (3rd Edition). San Antonio: TX-Harcourt assessment.

Bernhardt, B. M., Kemp, N., \& Werker, J. F. (2007). Early word-object associations and later language development. First Language, 27(4), 315-328.

Bishop, D. V. M., Price, T. S., Dale, P. S., \& Plomin, R. (2003). Outcomes of early language delay: Il. Etiology of transient and persistent language difficulties. Journal of Speech, Language and Hearing Research, 46(3), 561-565.

Farrant, B. M., \& Zubrick, S. R. (2012). Early vocabulary development: The importance of joint attention and parent-child book reading. First Language, 32(3), 343364.

Feldman, H. M., Dollaghan, C. A., Campbell, T. F., Kurs-Lasky, M., Janosky, J. E., \& Paradise, J. L. (2000). Measurement properties of the MacArthur Communicative Development Inventories at ages one and two years. Child development, 71(2), 310-322.

Fenson, L. (2007). MacArthur-Bates Communicative Development Inventories: user's guide and technical manual: Paul H. Brookes Publishing Company.

Fernald, A., \& Marchman, V. A. (2012). Individual Differences in Lexical Processing at 18 Months Predict Vocabulary Growth in Typically Developing and LateTalking Toddlers. Child development.

Gampe, A., Liebal, K., \& Tomasello, M. (2012). Eighteen-month-olds learn novel words through overhearing. First Language, 32(3), 385-397.

Heilmann, J., Weismer, S. E., Evans, J., \& Hollar, C. (2005). Utility of the MacArthurBates Communicative Development Inventory in Identifying Language Abilities of Late-Talking and Typically Developing Toddlers. American Journal of Speech-Language Pathology, 14(1), 40-51.

Hulme, C., \& Snowling, M. J. (2009). Developmental Disorders of Language Learning and Cognition: Wiley-Blackwell.

Koster, C., Been, P. H., Krikhaar, E. M., Zwarts, F., Diepstra, H. D., \& van Leeuwen, T. H. (2005). Differences at 17 months: Productive language patterns in infants at familial risk for dyslexia and typically developing infants. Journal of Speech, Language, and Hearing Research, 48(2), 426 - 438.

Kristoffersen, K. E., \& Simonsen, H. G. (2012). Tidlig språkutvikling hos norske barn : MacArthur-Bates foreldrerapport for kommunikativ utvikling. Oslo: Novus.

Kristoffersen, K. E., Simonsen, H. G., Bleses, D., Wehberg, S., Jørgensen, R. N., Eiesland, E. A., \& Henriksen, L. Y. (2012). The use of the Internet in collecting CDI data-an example from Norway. Journal of child language, 1(1), 1-19.

Kristoffersen, K. E., Simonsen, H. G., Eiesland, E. A., \& Henriksen, L. Y. (2012). Utvikling og variasjon i kommunikative ferdigheter hos barn som lærer norsk - en CDI-basert studie. Norsk tidsskrift for logopedi(12), 34-43.

Kuhl, P. K., Conboy, B. T., Padden, D., Nelson, T., \& Pruitt, J. (2005). Early speech perception and later language development: implications for the" Critical Period". Language Learning and Development, 1(3-4), 237-264. 
Law, J., \& Roy, P. (2008). Parental report of infant language skills: A review of the development and application of the Communicative Development Inventories. Child and Adolescent Mental Health, 13(4), 198-206.

Lyon, G. R., Shaywitz, S. E., \& Shaywitz, B. A. (2003). Defining dyslexia, comorbidity, teacher's knowledge of language and reading. Annals of Dyslexia, 53(1), 114.

Lyytinen, H., Ahonen, T., Eklund, K., Guttorm, T., Kulju, P., Laakso, M.-L., . . . Viholainen, H. (2004). Early development of children at familial risk for Dyslexia-follow up from birth to school age. Dyslexia, 10(3), 146-178.

Lyytinen, H., Ahonen, T., Eklund, K., Guttorm, T. K., Laakso, M.-L., Leinonen, S., . . . Viholainen, H. (2001). Developmental pathways of children with and without familial risk for dyslexia during the first years of life. Developmental Neuropsychology, 20(2), 535-554.

Lyytinen, H., Aro, M., Eklund, K., Erskine, J., Guttorm, T., Laakso, M.-L., . . . Richardson, U. (2004). The development of children at familial risk for dyslexia: birth to early school age. Annals of Dyslexia, 54(2), 184-220.

Lyytinen, P., Eklund, K., \& Lyytinen, H. (2005). Language development and literacy skills in late-talking toddlers with and without familial risk for dyslexia. Annals of Dyslexia, 55(2), 166-192.

Lyytinen, P., Poikkeus, A.-M., Laakso, M.-L., Eklund, K., \& Lyytinen, H. (2001). Language development and symbolic play in children with and without familial risk for dyslexia. Journal of Speech, Language, and Hearing Research, 44(4), 873-885.

McNemar, Q. (1969). Psychological statistics (fourth edition). New York - London Sydney - Toronto: John Wiley and Sons, Inc.

Nash, H. M., Hulme, C., Gooch, D., \& Snowling, M. J. (2013). Preschool language profiles of children at family risk of dyslexia: continuities with specific language impairment. Journal of Child Psychology and Psychiatry, 54(9), 958968.

Nergård-Nilssen, T., \& Hulme, C. (2014). Developmental Dyslexia in Adults: Behavioural Manifestations and Cognitive Correlates. Dyslexia, 1-17. doi: 10.1002/dys.1477

Rescorla, L. (2002). Language and reading outcomes to age 9 in late-talking toddlers. Journal of Speech, Language and Hearing Research, 45(2), 360-371.

Rescorla, L. (2005). Age 13 language and reading outcomes in late-talking toddlers. Journal of Speech, Language and Hearing Research, 48(2), 459.

Rescorla, L. (2009). Age 17 language and reading outcomes in late-talking toddlers: Support for a dimensional perspective on language delay. Journal of Speech, Language, and Hearing Research, 52(1), 16-30.

Rescorla, L. (2011). Late Talkers: Do Good Predictors of Outcome Exist? Developmental Disabilities Research Reviews, 17(2), 141-150.

Rescorla, L., Roberts, J., \& Dahlsgaard, K. (1997). Late talkers at 2: Outcome at age 3. Journal of Speech, Language and Hearing Research, 40(3), 556-566.

Rice, M. L., Taylor, C. L., \& Zubrick, S. R. (2008). Language outcomes of 7-year-old children with or without a history of late language emergence at 24 months. Journal of Speech, Language and Hearing Research, 51(2), 394-407.

Richardson, U., Leppänen, P. H. T., Leiwo, M., \& Lyytinen, H. (2003). Speech perception of infants with high familial risk for dyslexia differ at the age of 6 months. Developmental Neuropsychology, 23(3), 385-397.

Scarborough, H. S. (1990). Very early language deficits in dyslexic children. Child development, 61(6), 1728-1743. 
Simonsen, H. G., Kristoffersen, K. E., Bleses, D., Wehberg, S., \& Jørgensen, R. N. (2014). The Norwegian Communicative Development Inventories: Reliability, main developmental trends and gender differences. First Language, 34(1), 323.

Snowling, M. J., Gallagher, A., \& Frith, U. (2003). Family risk of dyslexia is continuous: Individual differences in the precursors of reading skill. Child development, 74(2), 358-373.

Tabachnick, B. G., \& Fidell, L. S. (2013). Using multivariate statistics. Boston: Pearson.

Tamis-LeMonda, C. S., Baumwell, L., \& Cristofaro, T. (2012). Parent-child conversations during play. First Language, 0142723711419321.

Tamis LeMonda, C. S., Bornstein, M. H., \& Baumwell, L. (2001). Maternal responsiveness and children's achievement of language milestones. Child development, 72(3), 748-767.

Tomblin, J. B., Records, N. L., Buckwalter, P., Zhang, X., Smith, E., \& O'Brien, M. (1997). Prevalence of specific language impairment in kindergarten children. Journal of Speech, Language, and Hearing Research, 40(6), 1245-1260.

Torppa, M., Lyytinen, P., Erskine, J., Eklund, K., \& Lyytinen, H. (2010). Language development, literacy skills, and predictive connections to reading in Finnish children with and without familial risk for dyslexia. Journal of learning disabilities, 43(4), 308-321.

Tsao, F. M., Liu, H. M., \& Kuhl, P. K. (2004). Speech perception in infancy predicts language development in the second year of life: A longitudinal study. Child development, 75(4), 1067-1084.

van Alphen, P., de Bree, E., Gerrits, E., de Jong, J., Wilsenach, C., \& Wijnen, F. (2004). Early language development in children with a genetic risk of dyslexia. Dyslexia, 10(4), 265-288.

van der Leij, A., Bergen, E., Zuijen, T., Jong, P., Maurits, N., \& Maassen, B. (2013). Precursors of developmental dyslexia: an overview of the longitudinal Dutch dyslexia programme study. Dyslexia, 19(4), 191-213.

van Zuijen, T. L., Plakas, A., Maassen, B. A. M., Maurits, N. M., \& Leij, A. (2013). Infant ERPs separate children at risk of dyslexia who become good readers from those who become poor readers. Developmental science, 16(4), 554-563.

Weisleder, A., \& Fernald, A. (2013). Talking to Children Matters Early Language Experience Strengthens Processing and Builds Vocabulary. Psychological Science, 24(11), 2143-2152.

Westerlund, M., Berglund, E., \& Eriksson, M. (2006). Can severely language delayed 3-year-olds be identified at 18 months? Evaluation of a screening version of the MacArthur-Bates Communicative Development Inventories. Journal of Speech, Language and Hearing Research, 49(2), 237-247.

Zambrana, I. M., Pons, F., Eadie, P., \& Ystrom, E. (2013). Trajectories of language delay from age 3 to 5 : persistence, recovery and late onset. International Journal of Language \& Communication Disorders, 00(0), 1-13. 
Table 1. Overview over screening procedures.

\begin{tabular}{|c|c|c|c|c|c|c|}
\hline \multirow[b]{2}{*}{ Variable } & \multirow[b]{2}{*}{ Instrument } & \multirow[b]{2}{*}{ Setting } & \multicolumn{4}{|c|}{ Age } \\
\hline & & & 12 months & 15 months & 18 months & 24 months \\
\hline Receptive vocabulary & MCDI (WG) & Parent report & $\mathrm{X}$ & $\mathrm{X}$ & $\mathrm{X}$ & \\
\hline Productive vocabulary & MCDI (WG) & Parent report & $\mathrm{X}$ & $\mathrm{X}$ & $\mathrm{X}$ & \\
\hline Words produced & MCDI (WS) & Parent report & & & $\mathrm{x}$ & $\mathrm{x}$ \\
\hline Expressive communication & Bayley III (BSID) & Laboratory & & & & $\mathrm{x}$ \\
\hline
\end{tabular}

Note. MCDI (WG) = MacArthur Communicative Development Inventory - Words and Gestures. MCDI (WS) = MacArthur Communicative

Development Inventory - Words and Sentences. Bayley III (BSID) = The Bayley Scales of Infant Development, 3rd edition. 
Table 2. Descriptive statistics and group comparisons.

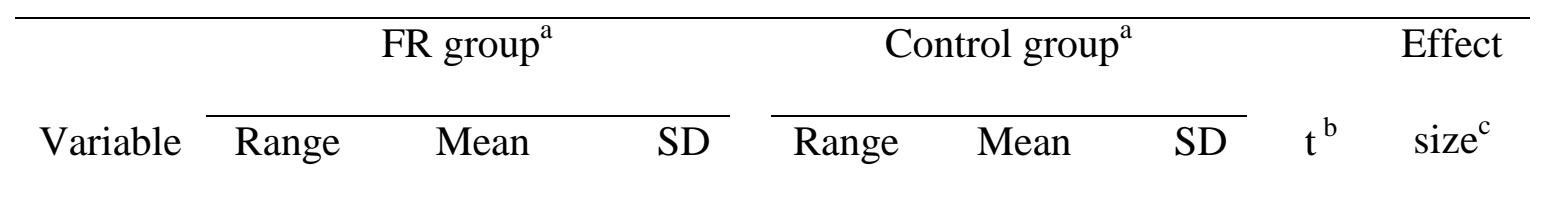

Receptive vocabulary (CDI Words and Gestures)

$\begin{array}{rrrrrrrrr}12 \mathrm{~m} & 0-108 & 29.18 & 31.52 & 4-86 & 33.60 & 24.35 & .53 & -.16 \\ 15 \mathrm{~m} & 0-237 & 69.59 & 57.97 & 20-248 & 96.29 & 58.08 & 1.64 & -.46 \\ 18 \mathrm{~m} & 4-289^{\mathrm{d})} & 125.69 & 73.88 & 69-274 & 154.71 & 56.13 & 1.53 & -.44\end{array}$

Productive vocabulary (CDI Words and Gestures)

$\begin{array}{llrrrrrrr}12 \mathrm{~m} & 0-15 & 5.04 & 4.55 & 0-12 & 4.70 & 3.48 & -.28 & .08 \\ 15 \mathrm{~m} & 0-80^{\mathrm{d}} & 12.88 & 9.67 & 3-22 & 11.10 & 5.51 & -.77 & .23 \\ 18 \mathrm{~m} & 3-177^{\mathrm{d}} & 33.66 & 27.21 & 7-82 & 30.00 & 22.48 & -.51 & .15\end{array}$

Words produced (CDI Words and Sentences)

$\begin{array}{rrrrrrrrr}18 \mathrm{~m} & 4-292^{\mathrm{d}} & 41.90 & 36.90 & 9-92 & 37.19 & 26.18 & -.51 & .15 \\ 24 \mathrm{~m} & 12-732 & 259.06 & 176.34 & 49-492 & 228.67 & 141.62 & -.66 & .19\end{array}$

Expressive communication (Bayley III) 


$\begin{array}{lllllllll}24 \mathrm{~m} & 23-37 & 31.50 & 3.93 & 24-37 & 31.71 & 4.29 & .19 & -.05\end{array}$

${ }^{a}$ Number of subjects varied due to missing data in single measures: the FR group, $n=28-32$ and the control group, $n=20-21$.

${ }^{\mathrm{b}}$ All group comparisons were non-significant, $\mathrm{p}>.05$.

${ }^{c}$ Effect sizes were estimated with Cohen's d.

${ }^{\mathrm{d}}$ Identified as outlier and moved to the tail of the distribution in further analyses. 
Table 3a. Correlations between language measures the FR group ${ }^{\mathrm{a}}$.

\begin{tabular}{|c|c|c|c|c|c|c|}
\hline & \multirow{2}{*}{$\begin{array}{c}12 \text { months } \\
\text { Prod. }\end{array}$} & \multicolumn{2}{|c|}{15 months } & \multicolumn{2}{|c|}{18 months } & \multirow{2}{*}{$\begin{array}{c}24 \text { months } \\
\text { Prod. }\end{array}$} \\
\hline & & Rec. & Prod. & Rec. & Prod. & \\
\hline & voc. & voc. & voc. & voc. & lang. & lang. \\
\hline \multicolumn{7}{|l|}{12 months } \\
\hline Receptive vocabulary & $.66^{* * * *}$ & $.69^{* * * *}$ & $.69^{* * * *}$ & $.82^{* * * *}$ & $.67^{* * * *}$ & $.52^{* *}$ \\
\hline Productive vocabulary & & $.54^{* * *}$ & $.61^{* * * *}$ & $.66^{* * *}$ & $.58^{* *}$ & $.50^{* *}$ \\
\hline \multicolumn{7}{|l|}{15 months } \\
\hline Receptive vocabulary & & & $.81^{* * * * *}$ & $.79^{* * * *}$ & $.56^{* *}$ & $.48^{* *}$ \\
\hline Productive vocabulary & & & & $.70^{* * * *}$ & $.74^{* *}$ & $.57^{* * *}$ \\
\hline \multicolumn{7}{|l|}{18 months } \\
\hline Receptive vocabulary & & & & & $.68^{* * *}$ & $.63^{* * *}$ \\
\hline Word production & & & & & & $.75^{* * * *}$ \\
\hline
\end{tabular}

Note: Correlations coefficients, which were different in the FR and control group according to difference test based on Fisher's z-transformed correlation coefficients (McNemar, 1969) are marked with bold. 
Table 3b. Correlations between language measures the control group ${ }^{\mathrm{a}}$

\begin{tabular}{|c|c|c|c|c|c|c|}
\hline & \multirow{2}{*}{$\begin{array}{c}12 \text { months } \\
\text { Prod. }\end{array}$} & \multicolumn{2}{|c|}{15 months } & \multicolumn{2}{|c|}{18 months } & \multirow{2}{*}{$\begin{array}{c}24 \text { months } \\
\text { Prod. }\end{array}$} \\
\hline & & Rec. & Prod. & Rec. & Prod. & \\
\hline & voc. & voc. & voc. & voc. & lang. & lang. \\
\hline \multicolumn{7}{|l|}{12 months } \\
\hline Receptive vocabulary & $.51^{*}$ & $.61^{* *}$ & -.04 & $.49^{*}$ & .14 & .34 \\
\hline Productive vocabulary & & .33 & $.49^{*}$ & $.45^{*}$ & .42 & $.58^{* *}$ \\
\hline \multicolumn{7}{|l|}{15 months } \\
\hline Receptive vocabulary & & & .04 & $.68^{* * *}$ & -.06 & .16 \\
\hline Productive vocabulary & & & & .36 & $.72^{* * *}$ & .34 \\
\hline \multicolumn{7}{|l|}{18 months } \\
\hline Receptive vocabulary & & & & & .40 & $.53^{*}$ \\
\hline Word production & & & & & & $.55^{* *}$ \\
\hline
\end{tabular}

Note: Correlations coefficients, which were different in the FR and control group according to difference test based on Fisher's z-transformed correlation coefficients (McNemar, 1969) are marked with bold.

${ }^{a}$ Number of subjects varied due to missing data in single measures: $n=20-21$. 
Table 4. Summary of Hierarchical Regression analysis for predicting productive language at age 24 months in the FR and Control group.

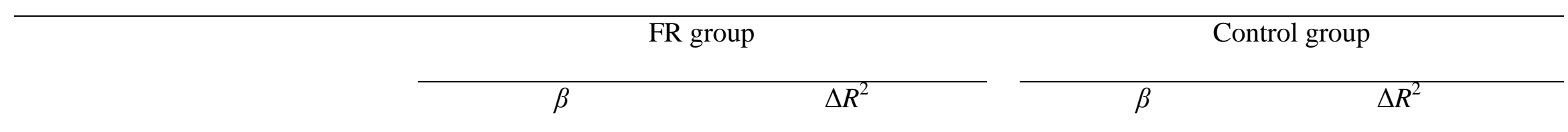

Step 1 (age 12 months)

Receptive vocabulary

$.28 * *$

ns

ns

Productive vocabulary

ns

.58

$.34 * *$

Step 2 (age 15 months)

Receptive vocabulary

ns

ns

ns

ns

Productive vocabulary

ns

ns

ns

ns

Step 3 (age 18 months)

Receptive vocabulary

Word production
.56

.55
$.08^{*}$

$.30 * * *$

$.65^{* * *}$ ns

ns ns

ns

$.34 * *$

$\mathrm{R}^{2}$

Note: 6 = standardized regression coefficient for the final model. The standardized beta for Receptive vocabulary at 12 months was $.52^{* *}$ when entered into the model at Step1.

${ }^{*} p<.05,{ }^{* *} p<.01, * * * p<.001$ 
Table 5. Predicting late talker group membership in the FR group $(n=32)$ using logistic regression analysis.

\begin{tabular}{|c|c|c|c|c|c|c|}
\hline Predictor & $\beta$ & $S E \beta$ & Wald & $d f$ & $p$ & Odds ratio \\
\hline Constant & 6.27 & 2.68 & 5.48 & 1 & .019 & 529.23 \\
\hline Productive vocabulary, 18 months & -2.48 & 0.98 & 6.36 & 1 & .012 & 0.08 \\
\hline
\end{tabular}

